\title{
BIOLOGIA DE Nystalea nyseus (CRAMER, 1775) (LEPIDOPTERA: NOTODONTIDAE) EM FOLHAS de Eucalyptus urophylla.
}

\author{
Teresinha Vinha ZANUNCIO ${ }^{1}$, José Cola ZANUNCIO ${ }^{1}$, Adalton Pinheiro \\ CRUZ $^{2}$, Eloisio VINHA ${ }^{3}$
}

\begin{abstract}
RESUMO - Essa pesquisa foi conduzida no laboratório de Entomologia Florestal da Universidade Federal de Viçosa à $25 \pm 2^{\circ} \mathrm{C}, 60 \pm 10 \%$ UR e fotoperíodo de $12 \mathrm{~L}: 12 \mathrm{E}$. O objetivo foi estudar a biologia de Nystalea nyseus (Cramer, 1775) (Lepidoptera: Notodontidae) em folhas de Eucalyptus urophylla. $N$. nyseus apresentou cinco estádios, com duração, média, de 3,99 \pm 0,$11 ; 3,80 \pm 0,10 ; 4,95 \pm 0,30 ; 5,96 \pm 0,21$ e $6,85 \pm 0,14$ dias, respectivamente. A duração total da fase larval foi de 25,5 dias. A fase de pré-pupa teve duração de $3,05 \pm 0,05 ; 3,08 \pm 0,06$ dias e a de pupa $14,75 \pm 0,45$ e 13,82 $\pm 0,29$ dias para machos e fêmeas, respectivamente. A viabilidade, dos ovos, foi de $74,72 \%$ e o período embrionário de $3,40 \pm 0,16$ dias. A longevidade de adultos, acasalados, foi de $6,71 \pm 0,74$ dias para machos e $9,14 \pm 0,96$ dias para fêmeas e razão sexual de 0,55 , ou seja uma fêmea para 0,81 macho.
\end{abstract}

Palavras-Chave: Desfolhador de eucalipto, Lepidoptera, Nystalea nyseus, Eucalyptus.

Biology of Nystalea nyseus (Cramer, 1775) (Lepidoptera: Notodontidae) in Eucalyptus urophylla Leaves.

ABSTRACT - Biological aspects of Nystalea nyseus (Cramer, 1775) (Lepidoptera: Notodontidae), a major Eucalyptus defoliator pest was studied under laboratory conditions at $25 \pm 2{ }^{\circ} \mathrm{C}, 60 \pm 10 \%$ UR and photophase 12L:12D. This species showed five instars with 3.99 $\pm 0.11 ; 3.80 \pm 0.10 ; 4.95 \pm 0.30 ; 5.96 \pm 0.21$ and $6.85 \pm 0.14$ days respectivelly and duration of total larval period of 25.55 days. Pre-pupal stage lasted $3.05 \pm 0.05$ and $3.08 \pm 0.06$ and pupal stage lasted $14.75 \pm 0.45$ and $13.82 \pm 0.29$ days for males and females, respectivelly. Egg duration period was $3.40 \pm 0.16$ days with $74.72 \%$ of viability. Mated adults longevity were $6.71 \pm$ 0.74 and $9.14 \pm 0.96$ days for males and females, respectivelly. Sexual ratio was 0.55 , or one female for 0,81 male.

Key-words: Eucaliptus defoliator, Lepidoptera, Nystalea nyseus, Eucalyptus.

\section{INTRODUÇÃO}

O Brasil ocupa o quarto lugar no mundo, em implantação de maciços florestais homogêneos (CLEMENTE, 1976) e devido a sua adaptabilidade e rápido crescimento o gênero Eucalyptus tem sido o mais usado, nesses plantios. Nas áreas plantadas, com esse gênero, tem-se observado crescimento do número de espéciespraga (ZANUNCIO, 1993), com destaque para as formigas cortadeiras e os lepidópteros desfolhadores.

Relatos sobre grandes surtos de lagartas desfolhadoras em plantios de eucalipto são feitos por ZANUNCIO \& LIMA (1975), MORAES \& SOARES (1981) e SANTOS et al. (1982). Nystalea nyseus (Cramer, 1775) (Lepidoptera: Notodontidae) tem sido coletada, com armadilhas luminosas, em diferentes regiões do Brasil sendo, normalmente, considerada praga

1 Universidade Federal de Viçosa, Departamento de Biologia Animal, 36571-000)-Viçosa, MG.

2 Jari Celulose S.A. - Almerim, 68240-000, Monte Dourado, PA.

? Universidade Federal de Viçosa, 36571-000, Viçosa, MG. 
secundária do eucalipto (ZANUNCIO et al. , 1991). No entanto, após um surto de grandes proporções, ocorrido em plantios de eucalipto, no norte do Espírito Santo e sul da Bahia (LARANJEIRO \& FUJIHARA, 1991) esta espécie passou a ser considerada praga primária.

A biologia de lagartas desfoIhadoras de eucalipto, tem sido estudada por vários autores (SANTOS et al., 1982; 1985; ZANUNCIO et al., $1990 ; 1992 a, c)$ que mostraram a necessidade desses dados para o controle de lagartas. Como a literatura não registra estudos sobre a biologia de $N$. nyseus, realizou-se esta pesquisa, para estudar-se os principais parâmetros biológicos dessa espécie.

Essa pesquisa faz parte do Programa Cooperativo para o Manejo Integrado de Pragas em Florestas (PC-MIP/ SIF) da Sociedade de Investigações Florestais (SIF, Viçosa, MG).

\section{MATERIAL E MÉTODOS}

Em maio de 1992, coletou-se lagartas e pupas de $N$. nyseus, em povoamento de Eucalyptus urophylla da Jari Celulose S.A. (Pará).

A biologia e o comportamento dessa espécie, foram estudados em laboratório à $25 \pm 2 \mathrm{C}, 60 \pm 10 \%$ UR e fotoperíodo de 12L:12E. As lagartas foram colocadas em gaiolas teladas de $30 \times 30 \times 30 \mathrm{~cm}$, com tampa de vidro e alimentadas, diariamente, com folhas de E. urophylla. As pupas e os adultos foram colocados em gaiolas com as mesmas características, das anteriores, contendo em seu interior, papel toalha recortado para a oviposição dos adultos. Como alimento era oferecido, em uma placa de Petri de $9,0 \mathrm{~cm}$ de diâmetro por $1,5 \mathrm{~cm}$ de altura, uma solução de mel a 10\% embebida em um chumaço de algodão.

As posturas foram acondicionadas em placas de Petri de $9,0 \mathrm{~cm}$ de diâmetro por $1,5 \mathrm{~cm}$ de altura, contendo em seu interior um chumaço de algodão embebido em água destilada para manutenção da umidade. Após a eclosão, quarenta lagartas, divididas em grupos de cinco, foram separadas em potes plásticos de $10 \mathrm{~cm}$ de altura por $10 \mathrm{~cm}$ de diâmetro $(500 \mathrm{ml})$, cuja tampa era telada no centro e em uma das laterais, introduzido, em um pequeno orifício, com a boca voltada para dentro do copo, um tubo de 2 $\mathrm{ml}$, tipo anestésico contendo água e uma folha de eucalipto. A utilização de cinco lagartas por copo evita a perda da repetição no caso de morte de uma ou mais lagartas. Na mesma linha de raciocínio não se deve utilizar maior número de lagartas por repetição devido ao espaço disponível nos copos plásticos. A partir do terceiro estádio as lagartas foram transferidas para gaiolas teladas de 21 $\times 21 \times 21 \mathrm{~cm}$, onde foram mantidas até o último estádio.

A medição da cápsula cefálica, após cada muda, foi feita com uma ocular micrométrica com precisão de $0,05 \mathrm{~mm}$, acoplada à uma lupa binocular, e o comprimento da lagarta medido com uma régua milimetrada.

As pupas foram individualizadas em potes plásticos $(500 \mathrm{ml})$, medidas, 
pesadas e sexadas, observando-se a duração dessa fase para machos e fêmeas. Após a emergência, os casars foram mantidos, usando-se a mesma metodologia da criação, para obtenção dos parâmetros biológicos da fase adulta, como longevidade, razão sexual, 'período de incubação, viabilidade dos ovos e características morfológicas.

Adultos de $N$. nyseus, utilizados nesse estudo, foram depositados no museu de entomologia da Universidade Federal de Viçosa, Viçosa, MG, estando disponíveis para estudos futuros.

\section{RESULTADOS E DISCUSSÃO}

\section{Características dos ovos}

Os ovos são verde-escuros. Após 24 horas tornam-se manchados de vermelho e com, aproximadamente, 48 horas ficam vermelho-escuros. Através do córion pode-se observar três linhas brancas, que também, estão presentes nas futuras lagartas.

$\mathrm{O}$ ovo é arredondado, medindo $1,16 \mathrm{~mm}$ de comprimento e $1,19 \mathrm{~mm}$ de largura, com um pequeno achatamento em uma das faces. Apresenta um período de incubação de 3,40 $\pm 0,16$ dias e viabilidade de $74,72 \%$. Os ovos foram encontrados, espalhados, e com maior frequência nas extremidades das folhas de eucalipto.

\section{Fase larval}

As lagartas de $N$. nyseus são conhecidas como "lagarta dragão", devido às protuberâncias no dorso e, principalmente, nos últimos segmentos abdominais. Nessas regiões, essas protuberâncias adquirem a forma de uma cabeça, lembrando um "dragão". Esta espécie apresentou cinco estádios, com duração média de 25,55 dias com maior crescimento do corpo do quarto para o quinto estádio. A razão de crescimento da cápsula cefálica variou de 1,42 a 1,60 sendo maior do primeiro para o segundo estádio (Tab. 1).

No primeiro estádio, as lagartas são de aspecto gelatinoso. Apresentam cabeça preta brilhante com minúsculas cerdas brancas; corpo marrom avermelhado dividido em 12 segmentos com duas linhas brancas paralelas ao longo do dorso, até a última falsa perna $e$, nas laterais quatro linhas. Do sexto ao nono segmentos, apresentam quatro falsas pernas pretas e a parte do abdome, após a última falsa perna, se mantém elevada formando um angulo de mais ou menos 90 graus com o plano do dorso. O final do abdome apresenta duas cerdas pretas com minúsculos pelos brancos, em forma de tesoura. Nesse estádio, as lagartas alimentam-se raspando as folhas e, quando em repouso, se enrolam como um caracol. Apresentam comprimento médio do corpo de $5,11 \mathrm{~mm}$.

Nos segundo e terceiro estádios as lagartas são muito semelhantes às do estádio anterior, porém, apresentam espiráculos pretos com peritrema de tonalidade mais clara que o corpo e na parte dorsal do quinto ao oitavo segmentos uma pequena elevação. 
Tabela 1. Características da Fase Larval de Nystalea nyseus à $25 \pm 2^{\circ} \mathrm{C}, 60 \pm 10 \%$ UR e Fotoperíodo de 12L:12E. Viçosa, Minas Gerais, 1992.

\begin{tabular}{|c|c|c|c|c|c|}
\hline \multirow[b]{2}{*}{ ESTÁDIO } & \multirow[b]{2}{*}{$\begin{array}{l}\text { Duração } \\
\text { (dias) }\end{array}$} & \multicolumn{2}{|c|}{ CÁPSULA CEFÁLICA } & \multicolumn{2}{|c|}{ CORPO DA LAGARTA } \\
\hline & & $\begin{array}{l}\text { Tamanho } \\
(\mathbf{m m})\end{array}$ & $\begin{array}{c}\text { Razão de } \\
\text { Crescimento }\end{array}$ & $\begin{array}{l}\text { Comprimento } \\
\text { Inicial (mm) }\end{array}$ & $\begin{array}{c}\text { Razão de } \\
\text { Crescimento }\end{array}$ \\
\hline 1 & $3,99 \pm 0,11$ & 0,77 & - & 5,11 & - \\
\hline$\|$ & $3,80 \pm 0,10$ & 1,23 & 1,60 & 7,86 & 1,53 \\
\hline III & $4,95 \pm 0,30$ & 1,80 & 1,46 & 11,30 & 1,37 \\
\hline IV & $5,96 \pm 0,21$ & 2,71 & 1,51 & 15,45 & 1,37 \\
\hline V & $6,85 \pm 0,14$ & 3,84 & 1,42 & 26,89 & 1,74 \\
\hline
\end{tabular}

Comprimento do corpo de 7,86 e $11,30 \mathrm{~mm}$, respectivamente.

No quarto estádio, a lagarta é cinza, apresentando na região dorsal, manchas brancas por todo o corpo; uma mancha preta entre o primeiro e terceiro segmentos e manchas verdes entre o sétimo e nono. Do quinto ao oitavo segmentos, estão presentes três elevações em forma de ganchos e no último, uma, em forma de cone (Fig. 1). Os espiráculos são pretos e o comprimento médio do corpo de $15,45 \mathrm{~mm}$.

No quinto estádio a mancha preta, presente na região dorsal, apresenta-se circundada por fileiras de manchas brancas. As lagartas apresentam coloração mais definida sendo cinza clara nos três primeiros segmentos, esverdeadas no dorso e vinho nas laterais do sextø ao décimo segmentos. Os espiráculos são elípticos, formado por linhas escuras e claras, com o peritrema preto. Comprimento médio do corpo de
26,89 mm (Tab. 1).

Tanto no campo como no laboratório as lagartas apresentam cores muito variadas sendo porém, facilmente, identificadas pelas expansões na parte dorsal do abdome.

\section{Pré-Pupa}

$\mathrm{Na}$ fase de pré-pupa as lagartas tecem um casulo com fios de seda, de coloração laranja, entre duas folhas de eucalipto, podendo servir para identificá-las no campo. Esta fase tem duração média de 3,05 dias.

\section{Pupa}

As pupas recém-formadas apresentam, nas primeiras horas, cor verde na região da cabeça, marrom no abdome e verde-clara na parte inferior do tórax, tornando-se preta brilhante, com o passar dos dias. $\mathrm{O}$ comprimento, largura e peso das pupas que deram origem a machos foram de $27,11 \pm 0,26 \mathrm{~mm} ; 5,55 \pm 0,17$ 


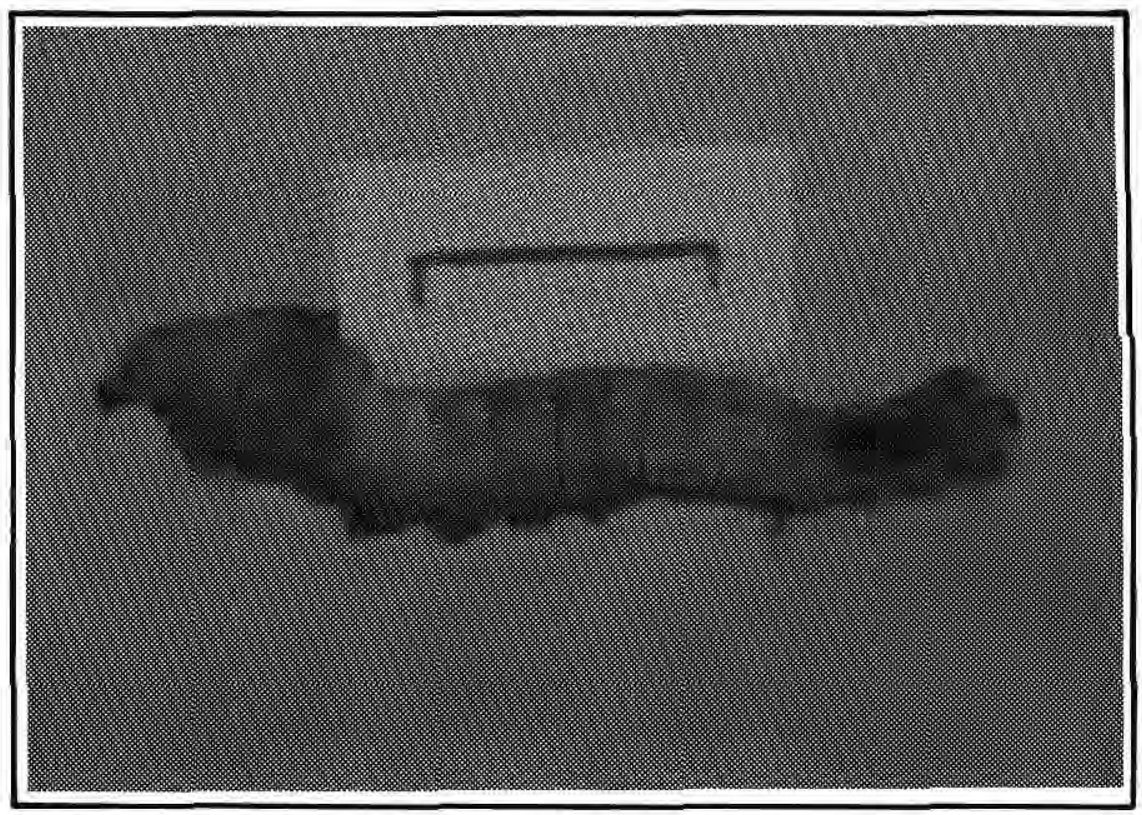

Figura 1. Lagarta de quinto estádio de Nystalea nyseus (Lepidoptera: Notodontidae),

$\mathrm{mm}$ e $0,66 \pm 0,01 \mathrm{~g}$ e a fêmeas de $27,18 \pm 0,29 \mathrm{~mm} ; 5,63 \pm 0,20 \mathrm{~mm} \mathrm{e}$ $0,70 \pm 0,04 \mathrm{~g}$, respectivamente. Esta fase durou, em média, $14,75 \pm 0,45$ e 13,82 $\pm 0,29$ dias para machos e fêmeas, respectivamente e viabilidade de $100 \%$ (Tab, 2).

\section{Fase Adulta}

Os adultos são semelhantes, no aspecto geral do corpo, possuindo em média, $51,2 \pm 0,5 \mathrm{~mm}$ de envergadura para machos e fêmeas. Antenas filiformes de, aproximadamente, $15 \mathrm{~mm}$ de comprimento para ambos os sexos. Abdome piloso de coloração cinza clara na região dorsal e amarela na ventral. Asas anteriores e posteriores com manchas pretas, concentradas na região central, bordas cinzas e interior amarela. Os adultos, quando molestados, tem um comportamento típico de tanatose. No campo, ficam imóveis, nos galhos de eucalipto, mimetizando um galho quebrado, sendo difícil localizá-los (Fig. 2).

A longevidade foi de $6,71 \pm 0,74$ e 9,14 $\pm 0,96$ dias para machos e fêmeas, respectivamente e a razão sexual de 0,55 , ou seja uma fêmea para cada 0,81 machos.

Dependendo da região do Brasil, onde são coletados, os adultos de $N$. nyseus apresentam a parte anterior da cabeça com coloração marrom ou preta. Há necessidade de estudar-se esta variação pois podem tratar-se de espécies diferentes que tem sido tratadas como uma única.

\section{Distribuição Geográfica e Flutuação Populacional}

N. nyseus foi coletada no Maranhão; em Minas Gerais (Montes 
Tabela 2. Características da Fase de Pupa de Nystalea nyseus. Viçosa, Minas Gerais, 1992.

\begin{tabular}{|c|c|c|c|c|c|}
\hline & & $\begin{array}{l}\text { COMPRIMENTO } \\
(\mathrm{mm})\end{array}$ & $\begin{array}{l}\text { LARGURA } \\
(\mathrm{mm})\end{array}$ & Peso (g) & Duração (dias) \\
\hline & Macho & $27,11 \pm 0,26$ & $5,55 \pm 0,17$ & $0,66 \pm 0,01$ & $14,75 \pm 0,45$ \\
\hline Pupa & Fêmea & $27,18 \pm 0,29$ & $5,63 \pm 0,20$ & $0.70+0.04$ & $13.82+0.29$ \\
\hline
\end{tabular}

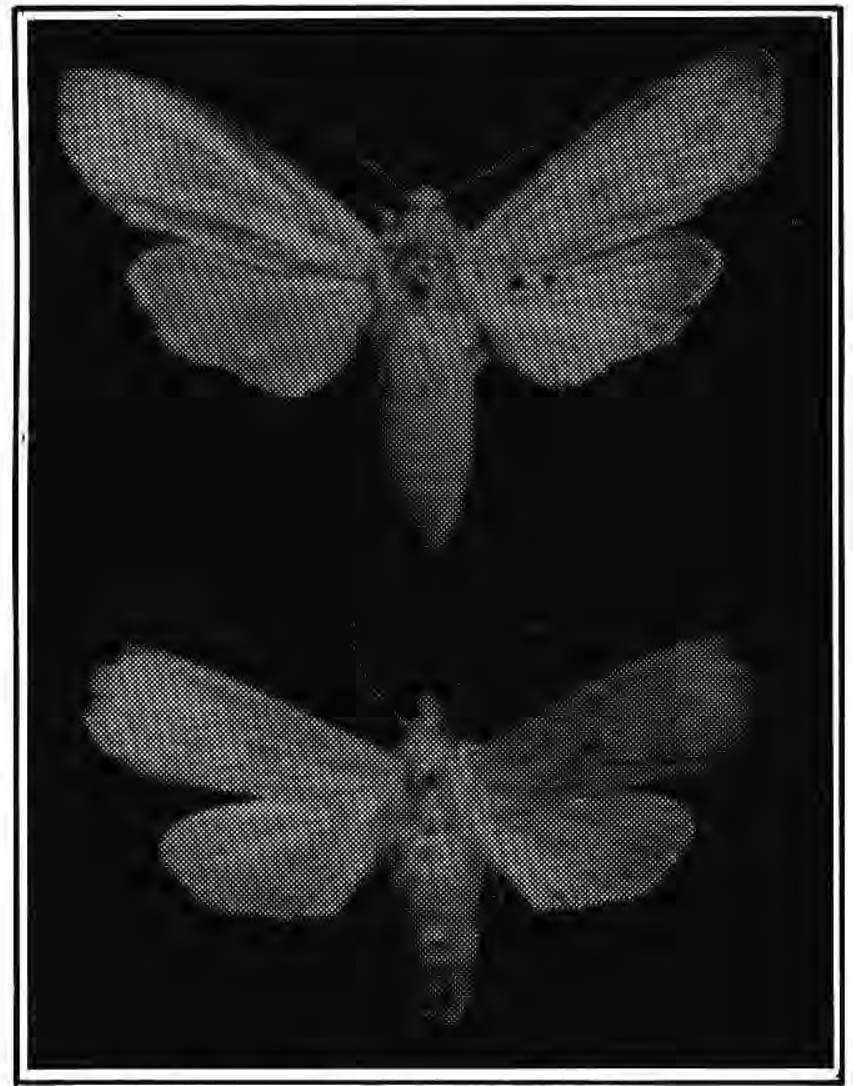

Figura 2. Adultos de Nystalea nyseus (Lepidoptera: Notodontidac).

Claros, Três Marias e Guanhães); em Goiás (Niquelândia); Pará (Monte Dourado); Espírito Santo e Bahia. Em coletas quinzenais, com armadilhas luminosas, os meses de maior ocorrência foram janeiro, maio e abril (Montes Claros); março (Três Marias, Maranhão e Bahia); abril (Pará e
Goiás) e novembro (Guanhães).

$N$. nyseus adquiriu maior importância após sua ocorrência em condições de surto no norte do Espírito Santo, sul da Bahia e norte do Pará. Nos dois primeiros locais, essa espécie foi controlada com equipamento tratorizado com 
aplicação de 500 gramas de Bacillus thuringiensis por hectare, na formulação pó molhável, misturado a oito quilos de talco por polvilhadeira (LARANJEIRO \& FUJIHARA, 1991). Em outro surto, registrado no Pará, essa espécie foi controlada com a aplicação aérea de $B$. thuringiensis em formulação oleosa, deltametrina e permetrina, com bons resultados (ZANUNCIO et al. 1992b).

\section{AGRADECIMENTOS}

Ao Conselho Nacional de Desenvolvimento Científico e Tecnológico $(\mathrm{CNPq})$ e à Fundação de Amparo à Pesquisa do Estado de Minas Gerais (FAPEMIG) pelas bolsas e auxílios concedidos; à Jari Celulose S.A. e à Sociedade de Investigações Florestais (SIF) pelo apoio na realização desse trabalho.

\section{Bibliografia citada}

CLEMENTE, A. M. 1976. Atualidades, potência florestal. Silvicultura, 1(3):10-3.

LARANJEIRO, A. J.; FUJIHARA, Y. S. P. 1991. Monitoramento de foco de Nystalea nyseus (Lepidoptera: Notodontidae) em plantios de Eucalyptus spp. In: Resumos do $8^{\circ}$ Congresso Brasileiro de Entomologia. Sociedade Entomológica do Brasil, Recife, p484.

MORAES, G. W. G.; SOARES, L. A. 1981. Ciclo biológico e consumo foliar de Psorocampa denticulata, Schaus (Lepidoptera: Notodontidae): lepidóptero desfolhador de eucalipto, In: Resumos do $7^{\circ}$ Congresso Brasileiro de Entomologia. Sociedade Entomológica do Brasil, Fortaleza, p14.

SANTOS, G. P.; ZANUNCIO, J. C. \& ANJOS, N. 1982. Novos resultados da biologia de
Psorocampa denticulata Schaus (Lepidoptera:Notodontidae), desfolhadora de Eucalyptus spp. Revista Árvore, 6(2) :121-132.

SANTOS, G. P.; ANJOS, N.; ZANUNCIO, J. C. 1985. Biologia de Apatelodes sericea (Lepidoptera:Geometridae), desfolhador de eucalipto, Revista Árvore, 9(2) :171179.

ZANUNCIO, J. C.; LIMA, J. O. G. 1985. Ocorrências de Sarsina violascens (Lepidoptera: Lymantriidae) em eucaliptos de Minas Gerais. Brasil Florestal, 6(23):4850.

ZANUNCIO, J. C.; GARCIA, J. F.; SANTOS, G. P.; ZANUNCIO, T. V. NASCIMENTO, E. C. 1990. Biologia e consumo foliar de lagartas de Euselasia apisaon ( D a I m a n, 1823 ) (Lepidoptera:Riodinidae) em Eucalyptus sp. Revista Árvore, 14(1):45-54.

ZANUNCIO, J. C.; SANTANA, D. L. Q.; SANTOS, G. P.; SARTôRIO, R. C.; ANJOS, N. 1991. Levantamento e flutuação populacional de lepidópteros associados à eucaliptocultura: II - Região do Alto São Francisco, M.G. Anais da Sociedade Entomológica do Brasil, 20(2) :283-292.

ZANUNCIO, J. C.; BATISTA, L. G.; SANTOS, G. P.; GASPERAZZO, W. L. 1992a. Biologia de Dirphia rosacordis (Lepidoptera: Saturniidae) em folhas de eucalipto. Revista Arvore, 16(1):112-117.

ZANUNCIO, J. C.; GUEDES, R. N. C.; CRUZ, A. P; MOREIRA, A. M. 1992 b. Eficiência de Bacillus thuringiensis e de deltametrina, em aplicação aérea, para o controle de Thyrinteina arnobia Stoll, 1782 (Lepidoptera: Geometridae) em eucaliptal do Pará. Acta Amazonica, 22(4) :485-492.

ZANUNCIO, J. C.; SANTOS, G. P.; SARAIVA, R. S.; ZANUNCIO, T. V. 1992c, Ciclo de vida e consumo foliar de Sarsina violascens (Lepidoptera: Lymantriidae) an Eucalyptus urophylla. Revista Brasileira de Entomologia, 36(4) :843850. 
ZANUNCIO, J. C. (ed.). 1993. Lepidoptera Desfolhadores de Eucalipto: Biologia, Ecologia e Controle. Sociedade de Investigações Florestais e Instituto de Pesquisas e Estudos Florestais. 141 p. 